\title{
Drawings of very preterm-born children at 5 years of age: a first impression of cognitive and motor development?
}

\author{
Sasja Schepers • Maja Deković • Max Feltzer • \\ Martin de Kleine • Anneloes van Baar
}

Received: 8 December 2010 / Accepted: 7 April 2011 /Published online: 7 May 2011

(C) The Author(s) 2011. This article is published with open access at Springerlink.com

\begin{abstract}
Introduction The aim of this study was to examine differences in drawing skills between very preterm and term children, and to determine whether very preterm children's cognitive and motor development is reflected in the draw-a-person test (DAP) at age 5. Seventy-two very preterm children (birth weight $<1,500 \mathrm{~g}$ and/or gestational age $<32$ weeks) and 60 term children at 5 years of age were compared on the DAP. Cognitive and motor skills of the very preterm children had been assessed four times, at 1/2, 1, 2, and 5 years of age. Very preterm children showed a developmental delay in drawing ability. Structural equation modeling revealed a positive relation between both cognitive as well as motor development and the DAP.

Conclusion The DAP could be a crude parameter for evaluating cognitive and motor deficits of very preterm children. A worrisome result should be followed by more standardized tests measuring cognitive and motor skills.
\end{abstract}

Electronic supplementary material The online version of this article (doi:10.1007/s00431-011-1476-8) contains supplementary material, which is available to authorized users.

S. Schepers $(\bowtie) \cdot$ M. Deković $\cdot$ A. van Baar

Department of Pedagogical and Educational Sciences,

Faculty of Social Sciences, Utrecht University,

PO Box 80140, 3508 TC Utrecht, The Netherlands

e-mail: sasjaschepers@hotmail.com

\section{Feltzer}

Department of Developmental Psychology, Tilburg University,

Tilburg, The Netherlands

M. de Kleine

Department of Neonatology, Máxima Medical Center,

Veldhoven, The Netherlands
Keywords Prematurity · Development · Drawings . Structural equation modeling (SEM)

Children born very premature are at risk of developing neurodevelopmental impairments that may influence later developmental trajectories [36]. Very preterm children ( $<32$ weeks of gestation and/or a birth weight $<1,500 \mathrm{~g}$ ) experience developmental delays in motor skills [16, 21], have lower cognitive scores at school age [2], and show more behavioral problems [34, 37, 49] than full-term children. These developmental problems are found to persist into early adulthood [17]. Not only very preterm children with neurosensory impairments experience problems during development. Even children with minor neurodevelopmental impairments show problematic outcomes at school age [32]. Besides, very preterm boys tend to develop more cognitive and motor problems than very preterm girls $[44,51]$.

These developmental problems of very preterm children arise from a number of different, but related factors. Birth weight and gestational age are found to be inversely related to developmental problems. However, birth weight and gestational age must be considered in combination with other biomedical risk factors, like respiratory problems, cerebral problems, and infections [12]. In addition, environmental factors such as socioeconomic status (SES) may also contribute to the development of disabilities. Lower levels of maternal education and neighborhood income are found to increase the risk for a preterm birth [26, 31]. Furthermore, high SES parents generally stimulate their children more via skill-building activities, which in turn affect school achievement [11]. With increasing chronological age, these factors may influence performance more than biological risk factors $[48,51]$. 
Follow-up information of the children's functioning is important for a timely recognition of difficulties and a referral for intervention, in order to reduce further developmental delay. The follow-up of all very preterm children is expensive; hence, there is a need for screening instruments that are relatively simple to use and inexpensive. Often, developmental pediatricians or pediatric psychologists ask the child to make a drawing, while they can have a conversation with the parents of that child. Such drawings may reflect the important aspects of cognitive and visual-motor functioning [4]. Children's human figure drawings have been used to get an impression of a child's developmental level [6]. Recent scoring systems show good reliability and have sufficient validity for evaluating cognitive abilities [41] and behavioral disturbance [27-30]. While cognitive skills have been clearly recognized to be represented in children's drawings, motor skills are a necessary condition of the drawing process as well. Whereas cognitive and motor functioning can be seen as two separate constructs, some authors emphasize that they are fundamentally related to each other [14]. Several anatomical brain structures which were thought to operate independently from one another seem to participate in one and the same task. Relatively few preterm children show "pure" cognitive deficits or pure "motor" deficits. For example, preterm children with learning disabilities also show considerable fine motor difficulties [32], and children with cerebral palsy often show problems with attention and memory [24]. The content of motor input - which is dictated by cognitive engagement during the drawing process - is fundamental for the subsequent recognition of drawings [35]. Research on human figure drawings by very preterm children has been very rare. A single study on preterm children's drawings [40] showed that they scored lower on the "draw-a-person" test [DAP; 29] than full-term children.

In the present study, very preterm children's drawings of a person are compared to drawings of full-term children at age 5. This age is important, as children younger than 5 years of age often lack the cognitive skills to understand that drawings are dual in nature; that is children must comprehend that the image forms an object in itself that refers to something else at the same time [20, 23, 42].

This study aims to test (1) if very preterm children show a developmental delay in their drawing skills at 5 years of age compared to full-term children and (2) whether the drawings of very preterm children at early school age can provide an accurate impression of their cognitive and motor development, while taking into account important biological and social risk factors. First, it is predicted that very preterm-born children at age 5 , as a result of developmental delay, draw worse (i.e. less skilled and less detailed) than term-born children. Second, a positive association between very preterm children's cognitive and motor development over the first 5 years is expected. Third, the quality of drawings at age 5 is expected to be positively related to very preterm children's cognitive and motor development. Fourth, very preterm children with more risk factors at birth (biological or social) are expected to have slower cognitive and motor development and to draw worse at age 5 . Finally, a very preterm child with a worrisome drawing score at age 5 is in general expected to also show "at risk" scores on more elaborate tests of cognitive and motor functioning at that age.

\section{Method}

\section{Participants}

The sample of very preterm children used in this study was a subgroup of the participants in a project investigating a pediatrician's assessment tool [13]. The cohort was selected from children with a very low birth weight (i.e., $<1,500 \mathrm{~g}$ ) and/or a very short gestational age (i.e., <32 weeks) born at the neonatal intensive care unit of the Máxima Medical Centre, the Netherlands.

Follow-up information at 1/2, 1, 2, and 5 years of age was available for 72 very preterm-born children. Sixty term children were recruited from three elementary schools in the Netherlands at age 5. The background characteristics of very preterm and term children are presented in Table 1. The age ranged from 5.0 to $5.6(M=$ $5.1, \mathrm{SD}=.11)$ for the very preterm children and from 5.0 to 5.9 for the term children $(M=5.4, \mathrm{SD}=.30)$. On average, the very preterm children were younger than the term children, $F$ $(1,112)=51.51, p<.001, \eta^{2}=.32$. Very preterm and term children at age 5 did not differ with regard to gender, $\chi^{2}$ $(1)=3.06, p=.08$; ethnicity, $\chi^{2}(1)=.56, p=.45$; or maternal educational level, $\chi^{2}(3)=3.48, p=.32$. No significant differences for the drawing scores of very preterm children with and without visual impairment were found, so the drawings of these children were included in the analyses.

\section{Measures}

Drawing skills At age 5, the DAP was used. Very preterm and term children were asked to draw a person. The drawings were coded using Naglieri's [29] cognitive criteria. In this system, 14 features were rated on scales that range from 0 up to a maximum of $3,4,5$, or 7 points. Features included 12 body parts, clothing, and the attachment of body parts. Scoring criteria assessed the presence of body parts, level of detail of parts, and proportionality of parts. The maximum score that an individual could obtain was 64. Raw scores were converted to standard scores, with 
Table 1 Background characteristics of very preterm and full-term children

\begin{tabular}{|c|c|c|c|c|c|c|}
\hline & \multicolumn{3}{|c|}{ Very preterm } & \multicolumn{3}{|c|}{ Full term } \\
\hline & Mean & $\mathrm{SD}$ & $\%$ & Mean & SD & $\%$ \\
\hline Gestational age in weeks & 29.0 & 2.04 & & 39.56 & 1.71 & \\
\hline Birth weight in grams & 1,165 & 356.33 & & 3,414 & 532.69 & \\
\hline $\begin{array}{l}\text { Duration of NICU (neonatal intensive } \\
\text { care unit) hospitalization (days) }\end{array}$ & 32 & 25.72 & & - & - & \\
\hline Very small for gestational age $(<\mathrm{p} 2.3)$ & & & $16.7 \%$ & & & $0 \%$ \\
\hline Sex $(\%$ male $)$ & & & $56.9 \%$ & & & $40.0 \%$ \\
\hline Twins & & & $25.0 \%$ & & & $2 \%$ \\
\hline Severe problems CNS $(\mathrm{PVL}>1, \mathrm{IVH}>1)$ & & & $18.1 \%$ & & & - \\
\hline Use of oxygen at 36 weeks pma & & & $5.6 \%$ & & & - \\
\hline \multicolumn{7}{|l|}{ Vision } \\
\hline Normal & & & $80.6 \%$ & & & - \\
\hline Normal vision with glasses & & & $5.6 \%$ & & & - \\
\hline Impaired vision with glasses & & & $4.2 \%$ & & & - \\
\hline \multicolumn{7}{|l|}{ Maternal education } \\
\hline Low & & & $23.6 \%$ & & & $13.3 \%$ \\
\hline Average & & & $51.4 \%$ & & & $50.0 \%$ \\
\hline High & & & $15.3 \%$ & & & $20.0 \%$ \\
\hline Ethnicity (\% Dutch) & & & $95.8 \%$ & & & $90.0 \%$ \\
\hline
\end{tabular}

a mean score of 100 and a standard deviation of \pm 15 . Testretest reliability of this test is .74 [29]. Interrater reliability is judged good to excellent [18]. The correlation of the DAP with total IQ on the WISC-RN was found to be .40 [46].

Cognitive skills The cognitive skills of very preterm children were measured at 1/2, 1, 2, and 5 years. The Dutch version of the Bayley Developmental Scales [BOS 2-30; 45] was used at 1/2, 1, and 2 years. The cognitive skills were assessed with the mental developmental index of the BOS 230. Dutch norms, reliability, and validity of the BOS-2-30 were sufficient [45]. The cognitive functioning at age 5 was assessed with the short version of the Revised Amsterdam Children's Intelligence Test [RAKIT; 3]. This test showed a correlation of .93 with the full-scale test [3]. The concurrent validity with the WISC-R was .86 for total IQ.

Motor skills Very preterm children's motor development at $1 / 2,1$, and 2 years was measured with the psychomotor developmental index of the Dutch version of the BOS-2-30 [45]. At age 5, motor functioning was assessed with the Movement Assessment Battery for Children [M-ABC; 38]. The total score on the M-ABC was transformed for this study in such a way that higher scores implied better performance. Furthermore, variables representing motor functioning were standardized into $z$ scores, such that all variables on motor functioning had the same scale.

Background characteristics A list with demographical and neonatal characteristics was filled out by the parents of the term children. The parents of the very preterm children had provided background information as part of the larger project [13].

Multiple risk Perinatal data were collected for very preterm-born children based upon the hospital records. Several risk factors were selected based upon their relation to developmental outcome in very preterm children [5]. A multiple risk score was based on the following criteria: gestational age $\leq 27$ weeks, being very small for gestational age (gestational age-specific birth weight $<\mathrm{p} 2.3$, corrected for gender), severe cerebral problems (i.e., PVL, IVH grades 2, 3, and 4 [47] hydrocephalus, convulsions), severe respiratory problems (BPD, indicating need for oxygen at 36 weeks), severe infections (sepsis and NEC), being a boy, and having a low-educated mother. Each risk present resulted in one point, hence the range of possible scores individuals could attain on this variable varied from zero to seven.

\section{Procedure}

The institutional medical ethical review board of the hospital approved of the study, and a written parental consent was obtained. Tests on mental and psychomotor development were done at $1 / 2,1,2$, and 5 years of age by a developmental psychologist or a child physiotherapist. At age 5 , the drawings of very preterm and term children were collected. The drawings in the group of term-born children 
were administered in class by well-instructed teachers. For the very preterm children, this was part of the follow-up assessment.

\section{Analytic strategy}

The missing items were imputed for very preterm children with a maximum of three tests missing on the total of nine developmental tests done between $1 / 2$ and 5 years. In total, three very preterm children (4.2\%) had missing measures of cognitive and motor functioning at $1 / 2$ and 1 year of age. At age 2 , one very preterm child (1.4\%) missed the assessment of cognitive and motor functioning. At age 5, 12 children $(16.7 \%)$ missed the assessment of motor functioning, six $(8.3 \%)$ the assessment of cognitive functioning, and 19 (26.4\%) the DAP test. For the estimation of missing items, missing value analysis in SPSS was used. Little's [25] missing completely at random test was not significant, $\chi^{2}=82.04, d f=63, p=.06$, indicating that the data were missing at random and that it was safe to impute missing items. Next, maximum likelihood estimation was used to impute the missing values, which was implemented by the expectation maximization algorithm.

Analysis of variance was used to investigate whether very preterm children's drawing skills at age 5 were developmentally delayed compared to term children. Bivariate correlations were computed and a two-factor model was tested against a one-factor model with structural equation modeling, using Amos 16.0. In those models, cognitive and motor development of very preterm children was hypothesized to predict the score on the DAP, while taking into account multiple risk at birth. In the two-factor model, the first factor represented cognitive functioning measured at $1 / 2,1,2$, and 5 years. The second factor depicted motor functioning of very preterm children, again measured at $1 / 2,1,2$, and 5 years. In the one-factor model, indicators of cognitive and motor development were assumed to represent one factor. The model was considered to fit when the value of the $\chi^{2}$ statistic was insignificant $(p>.05)$ or when fit indices revealed an acceptable fit. Values of the root mean square error of approximation (RMSEA) less than .05 indicated a good fit, while values less than .08 indicated a reasonable fit [7]. The values of normed fit index and comparative fit index (CFI) greater than .90 indicated a reasonable fit of the model [19]. Bayes information criteria [BIC; 33] were used to decide on the fit of non-nested models; smaller values of BIC indicated a better fitting model. This index penalizes complexity of models [22].

Finally, sensitivity and specificity analyses were done for the DAP at age 5 in relation to the RAKIT and the $\mathrm{M}-\mathrm{ABC}$ to see if very preterm children who made a poor drawing also performed poorly on more elaborate tests of cognitive and motor functioning. At risk groups were indicated by a cut off score of $\geq 1$ SD below the norm on the DAP, RAKIT, or M-ABC and were compared to the normal functioning groups.

\section{Results}

Comparison of drawings of very preterm and term children

Table 2 contains the results for the DAP test at age 5. Very preterm children and term children differed significantly with regard to their score on the DAP, $F(1,128)=31.21$, $p<.001, \eta^{2}=.20$ (see also Fig. 1). Very preterm children had a lower mean score on the DAP test than term children. Also, a significant gender effect was found, $F$ $(1,128)=9.54, p=.002, \eta^{2}=.07$. Girls scored higher on the DAP than boys, both within the very preterm and the term group. No significant interaction effect was found between prematurity and gender, $F(1,128)=1.05, p=.307$. When age was used as a covariate, the same group differences were found.

Drawing skills of very preterm children in relation to cognitive and motor development

Table 3 contains bivariate correlations for the 72 very preterm children on their cognitive and motor scores at $1 / 2$, 1,2 , and 5 years; their drawing score at 5 years; and multiple risk at birth. Within the developmental domains, significant and moderate to high positive correlations were found between cognitive skills over time and between motor skills over time. Also between the developmental domains, significant and moderate to high positive correlations were found between cognitive and motor skills over time and at each time point. Furthermore, significant and small negative associations were found between multiple risk at birth and measures of cognitive and motor functioning at $1 / 2,1,2$, and 5 years. No association was found between multiple risk at birth and children's drawing score at age 5. With regard to the DAP, small positive associations were found between the DAP and measures of

Table 2 Means and standard deviations on the Draw-A-Person test of very preterm and full-term boys and girls at 5 years of age

\begin{tabular}{llrlllll}
\hline & \multicolumn{2}{l}{ Very preterm } & & & \multicolumn{2}{l}{ Full-term } & \\
\cline { 2 - 3 } \cline { 6 - 7 } & $M$ & SD & $N$ & & $M$ & \multicolumn{1}{l}{ SD } & $N$ \\
\hline Boys & 91.93 & 8.23 & 41 & & 100.32 & 9.38 & 25 \\
Girls & 95.73 & 10.54 & 31 & & 107.89 & 12.91 & 35 \\
Total & 93.57 & 9.42 & 72 & & 104.73 & 12.08 & 60 \\
\hline
\end{tabular}


Fig. 1 Drawings are illustrative of the average scores of boys and girls in both groups. Top Drawing by a term boy with a DAP test score of 101 (left) and a very preterm boy with a DAP test score of $90($ right $)$ at 5 years of age. Bottom Drawing by a term girl with a DAP test score of 109 (left) and a very preterm girl with a DAP test score of 97 (right) at 5 years of age

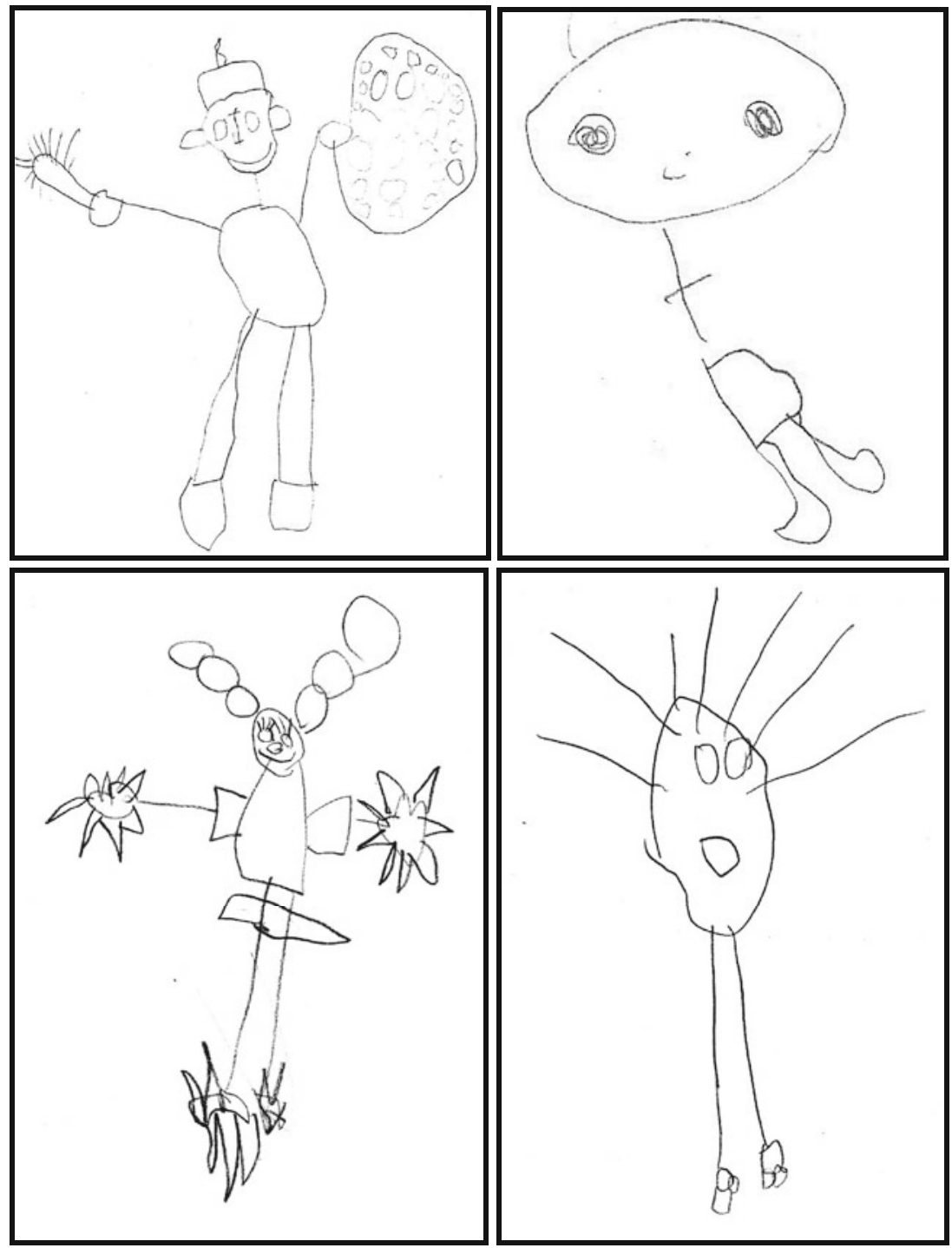

Table 3 Bivariate correlations between study variables in very preterm children at 1/2, 1, 2, and 5 years of age

\begin{tabular}{|c|c|c|c|c|c|c|c|c|c|}
\hline & 1 & 2 & 3 & 4 & 5 & 6 & 7 & 8 & 9 \\
\hline 1. Multiple risk & - & & & & & & & & \\
\hline 2. MDI age $1 / 2$ & $-.28 * *$ & - & & & & & & & \\
\hline 3. MDI age 1 & $-.36 * * *$ & $.62 * * * *$ & - & & & & & & \\
\hline 4. MDI age 2 & $-.26^{* *}$ & $.58 * * * *$ & $.58 * * * *$ & - & & & & & \\
\hline 5. RAKIT age 5 & $-.22 *$ & $.45^{* * * *}$ & $.62 * * * *$ & $.81 * * * *$ & - & & & & \\
\hline 6. PDI age $1 / 2$ & $-.25 * *$ & $.73 * * * *$ & $.55 * * * *$ & $.46^{* * * *}$ & $.41 * * * *$ & - & & & \\
\hline 7. PDI age 1 & $-.29 * *$ & $.57 * * * *$ & $.57 * * * *$ & $.48 * * * *$ & $.46^{* * * *}$ & $.65 * * * *$ & - & & \\
\hline 8. PDI age 2 & $-.34 * * *$ & $.38 * * *$ & $.39 * * *$ & $.56 * * * *$ & $.51 * * * *$ & $.45 * * * *$ & $.69 * * * *$ & - & \\
\hline 9. M-ABC age 5 & $-.35 * * *$ & $.52 * * * *$ & $.66^{* * * * *}$ & $.67 * * * *$ & $.69 * * * *$ & $.53 * * * *$ & $.67 * * * *$ & $.67 * * * *$ & - \\
\hline 10. DAP age 5 & -.19 & $.26^{* *}$ & .18 & $.22 *$ & $.27 * *$ & .18 & $.22 *$ & $.21^{*}$ & $.26^{* *}$ \\
\hline
\end{tabular}

MDI Mental developmental index, RAKIT Revised Amsterdam Child Intelligence Test, PDI Psychomotor developmental index, $M$ - $A B C$ Motor assessment battery for children, DAP Draw-A-Person test

$* p<.10, * * p<.05, * * * p<.01 ; * * * * p<.001$ 
Fig. 2 Final one-factor model of cognitive and motor functioning over time in relation to drawing skills at age 5 , while taking into account multiple risk at birth. $\alpha$ not tested for statistical significance, $n s$ not significant. All relations were at $p<.05$, except for the relationship between multiple risk and the DAP, for which $p=.458$

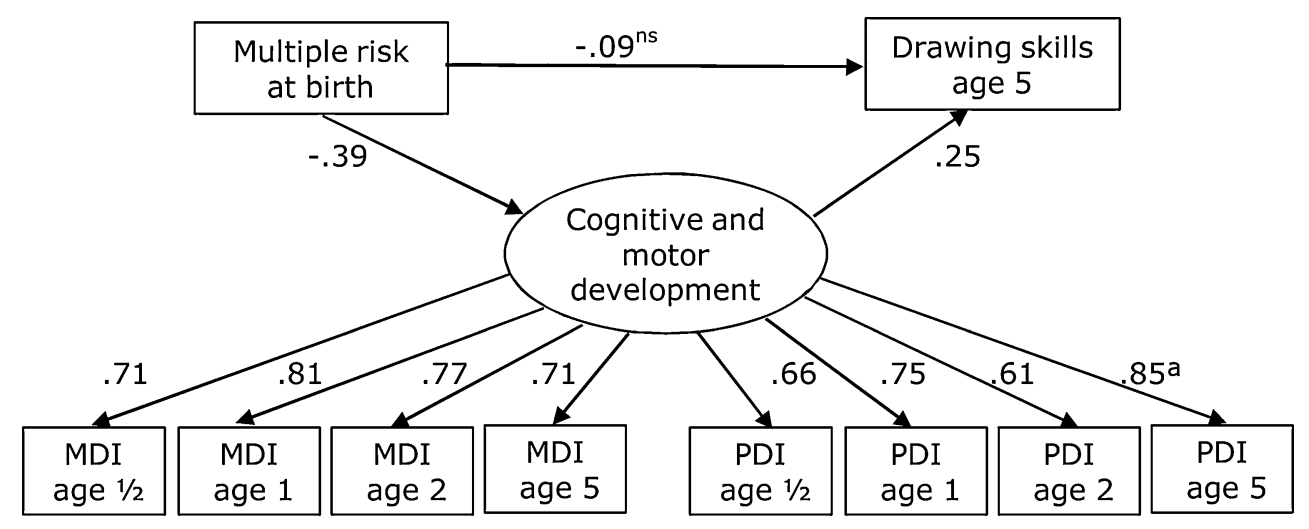

cognitive functioning at $1 / 2,2$, and 5 years and between the DAP and motor scores at 1, 2, and 5 years.

Structural equation modeling analysis revealed an acceptable fit of a two-factor model with cognitive and motor functioning over time predicting DAP scores at age 5, while taking into account multiple risk at birth, $\chi^{2}(21)=29.74, p=.097$, TLI $=.95, \mathrm{CFI}=.98, \mathrm{RMSEA}=.077, p=.235, \mathrm{BIC}=175.15$. For each set of indicators, the standardized factor loadings with each latent variable were all significant and relatively high, which suggests convergent validity. A strong association between the two factors $(r=.88, p<.001)$, however, suggested that the cognitive functioning and motor functioning were not two clearly distinct factors. Therefore, a one-factor model was also tested. This model had a slightly better fit to the data, $\chi^{2}$ $(24)=33.92, p=.086, \mathrm{TLI}=.95, \mathrm{CFI}=.98, \mathrm{RMSEA}=.076, p$ $=.226, \mathrm{BIC}=166.50$. For reasons of parsimony, we used the one-factor model for the subsequent analysis.

Figure 2 shows the estimated standardized parameter estimates for the hypothesized regression paths of the final one-factor model. A small to medium positive relation between the factor reflecting both cognitive and motor development, and children's score on the DAP test at age 5 was found. This indicates that children with worse cognitive and motor skills over time scored lower on the DAP test at age 5. The factor reflecting cognitive and motor functioning over time explained $11 \%$ of the variance in the DAP test at age 5. No relationship was found between multiple risk factors at birth and the DAP test at age 5. The

Table 4 Relation between results of very preterm children at age 5 on the DAP and the RAKIT

\begin{tabular}{llll}
\hline \multicolumn{2}{l}{ Cognitive Development } & & \\
\hline DAP & \multicolumn{2}{l}{ RAKIT } & Total \\
\cline { 2 - 3 } & At risk (+) & Not at risk (-) & \\
\hline At risk (+) & 4 & 10 & 14 \\
Not at risk (-) & 11 & 47 & 58 \\
Total & 15 & 57 & 72 \\
\hline
\end{tabular}

results did show a significant and moderate negative effect of multiple risks on cognitive functioning and motor functioning over time: very preterm children with more risk factors at birth had lower cognitive and motor scores over time. Multiple risk at birth explained $16 \%$ of the variance in the factor cognitive and motor development.

Tables 4 and 5 show the relation between the children identified as "at risk" for developmental problems by the DAP and the results on the RAKIT and the M-ABC at age 5 . Based on the sample of very preterm children studied here, we would expect from the sensitivity and specificity analyses that $27 \%(95 \% \mathrm{CI}: .09-.55)$ of the very preterm children with at risk scores on the DAP also have at risk cognitive scores on the RAKIT, while $82 \%(95 \% \mathrm{CI}$ : .70-.91) of the very preterm children with normal scores on the DAP would also attain normal cognitive scores on the RAKIT. With regard to the sensitivity and specificity of motor skills, we would expect that $23 \%$ (95\% CI: .11-.42) of the very preterm children with at risk scores on the DAP also have at risk motor scores on the M-ABC, while 83\% (95\% CI: .67-.92) of the very preterm children with normal scores on the DAP also would have normal motor scores on the M-ABC.

\section{Discussion}

Our findings show a developmental delay in drawings of very preterm children at 5 years. This is in line with the one

Table 5 Relation between results of very preterm children at age 5 on the DAP and the M-ABC

\begin{tabular}{llll}
\hline Motor Development & & & \\
\hline DAP & M-ABC & & Total \\
\cline { 2 - 3 } & At risk (+) & Not at risk (-) & \\
\hline At risk (+) & 7 & 7 & 14 \\
Not at risk $(-)$ & 24 & 34 & 58 \\
Total & 31 & 41 & 72 \\
\hline
\end{tabular}


study on drawing skills of preterm children [40] and with the other studies in which preterm children were found to be developmentally impaired in multiple domains of functioning [4, 43, 52]. Sex differences are found, but not solely for preterm boys, as in both groups, girls showed better drawing skills than boys.

Important is that cognitive and motor development in very preterm children is not found to be clearly distinct factors and both contribute to drawing skills. Although lessskilled drawings for very preterm children at early school age are related to lower cognitive and motor development, the DAP test is only partly (11\%) explained by the cognitive and motor developmental level of very preterm children. The DAP test turns out to be quite specific in identifying those very preterm children with normal cognitive and motor scores. However, a worrisome result on the DAP not always indicates a worrisome result on the RAKIT or the M-ABC, so we advice a more profound neuropsychological examination in these cases before conclusions can be made.

Other factors than cognition and motor functioning must be important in explaining drawing ability as well. Disposition for creativity, drawing experience, and personal interest for drawing (see Caroll's three stratum theory of intelligence $[8,9]$ ) may also be important. Only a modest correlation exists between general IQ and creativity [39]. However, a strong correlation was found between drawing ability and creativity [10]. Additionally, studies with regard to the background characteristics of creative children often reveal families that are focused on the child's needs, parents who are warm and sensitive, who provide a stimulating home life, and who are devoted to developing their child's abilities $[1,50]$. Giving birth to a very preterm child is, in general, accompanied by a lot of distress for parents. Research with preterm-born children showed that mothers of premature infants display less looking, smiling, vocalizing, and touching behavior toward their infants [15]. Thus, abilities such as creative giftedness and factors like a stimulating home environment might also contribute to drawing skills. Future research should study if other factors, such as creativity, contribute to drawing skills of very preterm-born children next to cognitive and motor skills. Finally, although administering the DAP test can be done relatively quickly as stated in the manual in 10 to $20 \mathrm{~min}$, we would prefer that the DAP test is used in multidisciplinary settings in collaboration with a psychologist.

\section{Conclusion}

A normal drawing score by a very preterm child at age 5 generally indicates normal cognitive and motor development at that age, while a clearly deviant drawing of a person could be a feasible warning signal to refer the child for further investigation of cognitive and motor skills with standardized tests.

Acknowledgments We thank all the parents and children for their participation and students Dave van Beek and Mario Boekhoudt. The study was supported by a grant of the Dutch Health Organisations Praeventiefonds, project number 28-2756, and ZorgOnderzoek Nederland (ZON), project number 1010004-20.

Conflicts of interest There are no conflicts of interest to disclose.

Open Access This article is distributed under the terms of the Creative Commons Attribution Noncommercial License which permits any noncommercial use, distribution, and reproduction in any medium, provided the original author(s) and source are credited.

\section{References}

1. Albert RS (1994) The achievement of eminence: a longitudinal study of exceptionally gifted boys and their families. In: Subotnik RF, Arnold KD (eds) Beyond Terman: contemporary studies of giftedness and talent. Ablex, Norwood, pp 282-315

2. Bhutta AT, Cleves MA, Casey PH, Cradock MM, Anand KJS (2002) Cognitive and behavioral outcomes of school-aged children who were born preterm: a meta-analysis. J Am Med Assoc 288:728-737

3. Bleichrodt N, Drenth PJD, Zaal JN, Resing WCM (1984) Revision Amsterdam child intelligence test. Swets \& Zeitlinger, Lisse

4. Böhm B, Lundequist A, Smedler A (2010) Visual-motor and executive functions in children born preterm: the Bender Visual Motor Gestalt Test revisited. Scand J Psych 51:376-384

5. Brazy JE, Eckerman CO, Oehler JM, Goldstein RF, O'Rand AM (1990) Nursery neurobiologic risk score: important factors in predicting outcome in very low birth weight infants. J Pediatr 118:783-792

6. Brown EV (1990) Developmental characteristics of figure drawings made by boys and girls ages five through eleven. Percept Mot Skills 70:279-288

7. Browne MW, Cudeck R (1993) Alternative ways of assessing model fit. In: Bollen KA, Long JS (eds) Testing structural equation models. Sage, Newbury Park, pp 136-162

8. Carroll JB (1993) Human cognitive abilities: a survey of factoranalytic studies. Cambridge University Press, New York

9. Carroll JB (1997) The three-stratum theory of cognitive abilities. In: Flanagan DP, Genschaft JL, Harrisson P (eds) Contemporary intellectual assessment. Guilford, New York, pp 122-130

10. Clark G, Zimmerman E (2001) Identifying artistically talented students in four rural communities in the United States. Gift Child Q 45:104-114

11. DeGarmo DS, Forgatch MS, Martinez CR (1999) Parenting of divorced mothers as a link between social status and boy's academic outcomes: unpacking the effects of socioeconomic status. Child Dev 70:1231-1245

12. De Kleine MJK, den Ouden AL, Kollée LAA, Ilsen A, van Wassenaar AG, Brand R, Verloove-Vanhorick SP (2007) Lower mortality but higher neonatal morbidity over a decade in very preterm infants. Paediatr Perinat Epidemiol 21:15-25

13. De Kleine MJK, Den Ouden AL, Kollee LAA, Van Der Sanden MW, Sondaar M, Van Kessel-Feddema BJ, Knuijt S, Van Baar AL, Ilsen A, Breur-Pieterse R, Briët JM, Brand R, Verloove- 
Vanhorick SP (2003) Development and evaluation of a follow up assessment of preterm infants at 5 years of age. Arch Dis Child $88: 870-875$

14. Diamond A (2000) Close interrelation of motor development and cognitive development and of the cerebellum and the prefrontal cortex. Child Dev 1:44-56

15. Feldman R, Eidelman AI (2007) Maternal postpartum behavior and the emergence of infant-mother and infant-father synchrony in preterm and full-term infants: the role of neonatal vagal tone. Dev Psychobiol 49:290-302

16. Foulder-Hughes LA, Cooke RWI (2003) Motor, cognitive and behavioural disorders in children born very preterm. Dev Med Child Neurol 45:97-103

17. Hack M, Flannery DJ, Schluchter M, Cartar L, Borawski E, Klein N (2002) Outcomes in young adulthood for very-low-birth-weight infants. N Engl J Med 346:149-157

18. Handler L (1996) The clinical use of drawings. In: Newmark C (ed) Major psychological assessment instruments, 2nd edn. Allyn \& Bacon, Boston, pp 206-293

19. Hu LT, Bentler PM (1999) Cutoff criteria for fit indices in covariance structure analysis: conventional criteria versus new alternatives. Struct Equ Mod 6:1-55

20. Jolley R (2008) Children's understanding of the dual nature of pictures. In: Lange-Kuttner C, Vinter A (eds) Drawing and the non-verbal mind: A life-span perspective. Cambridge University Press, Cambridge, pp 86-103

21. Jongmans M, Mercuri E, Henderson S et al (1996) Visual function of prematurely born children with and without perceptual motor difficulties. Early Hum Dev 45:73-82

22. Kline RB (2005) Principles and practice of structural equation modelling. Guilford, New York

23. Lange-Küttner C, Vinter A (eds) (2008) Drawing and the nonverbal mind: a life-span perspective. Cambridge University Press, Cambridge

24. Lewis V (2003) Development and disability, 2nd edn. Blackwell Publishers Ltd., Oxford

25. Little RJA (1988) A test of missing completely at random for multivariate data with missing values. J Am Stat Assoc 83:1198-1202

26. Luo Z, Wilkins R, Kramer MS (2006) Effect of neighbourhood income and maternal education on birth outcomes: a populationbased study. Can Mel Assoc J 174:1415-1421

27. Matto HC (2002) Investigating the validity of the draw-a-person: screening procedure for emotional disturbance: a measurement validation study with high-risk youth. Psychol Assess 14:221-225

28. McNeish TJ, Naglieri JA (1993) Identification of individuals with serious emotional disturbance using the draw a person: screening procedure for emotional disturbance. J Spec Educ 27:115-121

29. Naglieri JA (1988) Draw a person: a quantitative scoring system. Psychological Corporation, San Antonio

30. Naglieri JA, Pfeiffer SI (1992) Validity of the draw a person: screening procedure for emotional disturbance with a sociallyemotionally disturbed sample. Psychol Assess: J Consul Clin Psychol 4:156-159

31. Petersen CB, Mortensen LH, Morgen CS, Madsen M, Schnor O, Arntzen A, Gissler M, Cnattingius S, Andersen AN (2008) Socioeconomic inequality in preterm birth: a comparative study of the Nordic countries from 1981 to 2000. Paediatr Perinat Epidemiol 23:66-75

32. Powls A, Botting N, Cooke RW, Marlow N (1995) Motor impairment in children 12-13 years old with a birthweight less than $1250 \mathrm{~g}$. Arch Dis Child 71:F62-F66

33. Raftery AE (1993) Bayesian model selection in structural equations models. In: Bollen KA, Long JS (eds) Testing structural equation models. Sage, Newbury Park, pp 163-180
34. Reijneveld SA, de Kleine MJK, van Baar AL, Kollée LAA, Verhaak CM, Verhulst FC, Verloove-Vanhorick SP (2006) Behavioral and emotional problems in very preterm and very low birthweight infants at age 5 years. Arch Dis Child: Fet Neonat Ed 91:F423-F428

35. Ross J (2008) Drawing production, drawing re-experience and drawing re-cognition. In: Lange-Kuttner C, Vinter A (eds) Drawing and the non-verbal mind: a lifespanperspective. Cambridge University Press, Cambridge, pp 42-62

36. Saigal S, Doyle LW (2008) An overview of mortality and sequelae of preterm birth from infancy to adulthood. The Lancet 371:261-269

37. Samara M, Marlow N, Wolke D (2008) Pervasive behavior problems at 6 years of age in a total-population sample of children born at $\leq 25$ weeks of gestation. Pediatr 122:562-573

38. Smits-Engelsman BMC (1992) Movement ABC; Dutch Guide. Swets \& Zeitlinger, Lisse

39. Sternberg RJ, O'Hara LA (1999) Creativity and intelligence. In: Sternberg RJ (ed) Handbook of creativity. Cambridge University Press, Cambridge, pp 251-272

40. Strauss RS (2000) Adult functional outcome of those born small for gestational age: twenty-six-year follow-up of the 1970 British Birth Cohort. J Am Med Assoc 283:625-632

41. Ter Laak J, de Goede M, Aleva A (2005) The draw-a-person test: an indicator of children's cognitive and socioemotional adaptation? J Gen Psychol 166:77-93

42. Thomas GV, Jolley RP, Robinson EJ, Champion H (1999) Realist errors in children's responses to pictures and words as representations. J Exp Child Psychol 74:1-20

43. Van Baar AL, van Wassenaer AG, Briët JM, Dekker FW, Kok JH (2005) Very preterm birth is associated with disabilities in multiple developmental domains. J Pediatr Psychol 30:247255

44. Van Kessel-Feddema B, Sondaar M, de Kleine M, Verhaak C, van Baar AL (2007) Concordance between school outcomes and developmental follow-up results of very preterm and/or low birth weight children at the age of 5 years. Eur J Pediatr 166:693-699

45. Van der Meulen BF, Smrkovsky M (1983) BOS 2-30: Bayley Developmental Scales. Swets and Zeitlinger, Lisse

46. Van de Vijfeijken K (2005) Human figure drawing: the human figure drawing as a screen for cognitive development and socioemotional problems. Pits, Leiden

47. Volpe JJ (1995) Neurology of the newborn, 2nd edn. WB Saunders Company, Philadelphia

48. Weisglas-Kuperus N, Hille ETM, Duivenoorden HJ, Finken MJJ, Wit JM, Van Buuren S, Van Goudoever JB, Verloove-Vanhorick SP (2008) Intelligence of very preterm or very low birthweight infants in young adulthood. Arch Dis Child: Fet Neonat Ed 94: F196-F200

49. Williams, Lee \& Anderson (2010) Prevalence of motor skill impairment in preterm children who do not develop cebral palsy: a systematic review. Dev Med Child Neurol 52:232-237

50. Winner E (2000) The origins and ends of giftedness. Am Psychol 55:159-169

51. Wood NS, Costeloe K, Gibson AT, Hennessy EM, Marlow N, Wilkinson AR (2005) The EPICure study: associations and antecedents of neurological and developmental disability at 30 months of age following extremely preterm birth. Arch Dis Child: Fet Neonat Ed 90:F134-F140

52. Woodward LJ, Moor S, Hood KM et al (2009) Very preterm children show impairments across multiple neurodevelopmental domains by age 4 years. Arch Dis Child: Fet Neonat Ed 94:F339F344 